every respect to occupy such prominent position, with all the varied and arduous responsibilities, both executive and professional.

There ought to be no question in regard to the female insane in all our State institutions, in each of which there should be employed a female gynæcologist. Recent advances in medical science demand that all examinations, which not infrequently are required to be performed upon the female insane, should be conducted by one of their own sex.

The advantages and opportunities now extended in the colleges and hospitals in which women are educated are so thorough and complete in didactio and clinical instruction, especially so in regard to diseases of women, that there need be no difficulty in securing competent medical graduates, who ought to have charge of this part of the medical work in all our State institutions. It will be simply a question of time until every hospital will gladly avail itself of such an addition to its staff. Various causes have too long prevented this, but the advance cannot be long withheld, the advantages are too overwhelmingly patent, the medical superintendents and the trustees of the hospitals are too progressive and enlightened not to avail themselves of this much-needed and now well-recognized reform.

If such radical changes have been introduced into private hospitals for the insane with advantage, how much more appropriate are they likely to be in institutions built, supported and watched over by the taxpayer. At the Pennsylvania Hospital for the Insane the entire gynæcological work, medical and operative, has been for many years exclusively under the charge of the female prastitioner. The late Dr. Thomas S. Kirkbride, ever mindful of the great responsibility of his position to the patients under his charge and to the public in general, promptly, when it was found that competent women could be secured to attend to the local maladies of his female patients, relinquished all such treatment into the hands of a graduate of the Women's Medical College. The same course has been pursued by Dr. John B. Chapin, since his election as superintendent and physician-in-chief in 1884, with entire satisfaction to him and to the board of management."

Dr. Gerhard in Annwal Report of the Harrisburg Asylum, Penn., U.S.A.

\title{
ASSOCIATION EXAMINATIONS.
}

In our last number we gave the result of the examination for the Certificate of Efficiency in Psychological Medicine in England, Scotland, and Ireland, but the space at our command did not allow of our giving the written questions asked by the Examiners. We now supply them :-

\section{ENGLAND.}

JULY 18, 1889.

Examiners:

Dr. BLANDFORD and Dr. RAYATR.

PASS EXAMINATION.

1. Describe the various modes of feeding in the refusal of food by insane patients, and the diet you would prescribe. In what cases would you consider it necessary to feed immediately, and in what would you wait?

2. Describe the most common development of insanity occurring during lactation, and the treatment to be adopted in such cases.

3. Describe the physical symptoms in general paralysis of the insane.

4. Are hallucinations of sight and hearing symptoms of insanity? Do they occur in the sane? Can you distinguish the one class from the other? 
5. What is the immediate cause of death in cases of acute mania, acute melancholia, and general paralysis? What measures should be taken in order to avert it in each of these forms of insanity?

6. State your views as to the connexion of syphilis with insanity, especially general paralysis of the insane.

\section{SCOTLAND.}

JULY 17TH, 1889.

\section{PASS EXAMINATION.}

Examiner in Edinburgh : Dr. Yellowlens. Assessor : Dr. Clouston. Examiner in Aberdeen : Dr. RORIE.

Assessor : Dr. REID.

1. What are the circumstances which chiefly affect the prognosis in a case of insanity?

2. Define an illusion, a hallucination, and a delusion, and give an illustration of each. Mention the different kinds of hallucinations which are most frequent, and which are the most unfavourable as regards recovery.

3. In what forms of insanity does violent excitement usually occur, and how is it best treated?

4. Mention the forms of insanity which may occur in connection with physiological epochs in the life of a woman, and give a short sketch of each.

5. Mention the forms of insanity in which motor symptoms necessarily occur, stating the kind of motor synuptoms to be expected in each, and their relationship to the mental symptoms.

6. What medico-legal duties may devolve on the medical attendant in a case of insanity? And what are the most important points to be attended to in writing a certificate for placing the patient in an asylum ?

IRELAND.

JULY 31sT, 1889.

Examiners :

Conolly Norman, F.R.C.S.I., and Rnverose AtKnNs, M.A., M.D.

PASS EXAMINATION.

1. Give some of the most important classifications of insanity which have been put forward, and state, with your reasons, which you consider the soundest and most practically useful.

2. Describe in detail how you would conduct the clinical examination of an insane patient, in order to determine the possible causation, and the probable outcome of the case, physically and mentally.

3. Mention the different clinical groups of "States of Mental Depression," and sketch briefly the prominent distinguishing features of each.

4. What form of Mental Disease is the insanity occurring at the period of adolescence, likely to eventuate in? Describe its characteristics as regards its symptoms, course, and prognosis.

5. An insane patient has been refusing food-What indications would guide you in forming an opinion that the time had arrived when artificial feeding should be had recourse to ?

6. Mention some of the Hypnotics more recently introduced in the treatment of the insane; state the advantages or disadvantages of each; their doses, mode of administration, and the indications which call for their exhibition.

7. Discuss the following points connected with General Paralysis of the insane:- (a) general diagnosis; (b) importance of early diagnosis in medico-legal aspect; (c) proposed clinical division into stages; $(d)$ varieties of mental symptoms. 
8. Sketch a case of "Circular Insanity." What is the prognosis in such a case?

9. Define the following terms :-Delusion, hallucination, illusion, imperative concept.

10. You are called on to give an opinion as to testamentary capacity in a person of advanced age. What indications would gaide you in forming the opinion that senfle insanity existed ?

11. You examine a prisoner committed for an act of violence. Mention the circumstances which would induce you to believe that the person was(a) feigning insanity; (b) had acted under insane impulse; (c) suffered from transitory insanity; or (d) from moral insanity.

12. What is durbomatoma? In what affections is the condition most commonly found, and what are the theories as to its essential nature?

\section{THE NON-RESTRAINT QUESTION.}

We were under the impression that the discussion between Dr. Yellowlees and Dr. Alex. Robertson had exhausted itself in our last number. Fach physician had fally and freely expressed his views on a subject in regand to which they honestly hold different opinions. To continue the discussion would, we think, be little more than a repetition of the same statements, if not the same words, without adding any real force to the arguments employed by these able combatants. Dr. Robertson, however, wishes to make it unmistakably clear that he regards "locked gloves" as one form of mechanical restraint. $\Delta_{\mathrm{s}}$ he places in the same category "side arm dresses " and the "protection bed," and as Dr. Yellowlees recommends their use in exceptional crses, Dr. Robertson maintains that he was not in error in referring to " the considerable use of mechanical restraint" advocated by him. Another statement Dr. Robertson wishes to make, which is, that although he has been connected with an asylum which during the last five years has not had a larger number of patients than 125 , it was, during many years previonsly, licensed for 248 patients, a large proportion of whom were dangerous, both in respect of suicide and homicide.

\section{Correspondence.}

TO THR EDITORS OF The Journal of Mental Science.

SIrs,-I was unavoidably absent from the Annual Meeting of the MedicoPsychological Association, but have read with great interest in the October number of "The Journal of Mental Science" the very able Address of the President and the subsequent discussion on the subject which is probably uppermost in the minds of all asylum medical officers and others interested in the treatment of insanity at the present moment, viz., the advisability of establishing curative hospitals for occurring cases of insanity and for teaching purposes.

I think the tone in which the President alluded to the misrepresentations in Dr. Batty Tuke's paper in a recent number of the "Nineteenth Century" was most conciliatory; indeed, far too much so, and I was glad to find one or two speakers after him, notably Dr. Clouston, much more decided in disapproval. However, leaving Dr. Batty Tuke to digest the very cogent and wise refutations of his assertions about the total absence of genuine medical spirit in asylums, in the President's Address, I beg to note a few con- 